\title{
A sensitive and selective fluorescent probe for real-time detection and imaging of hypochlorous acid in living cells
}

Pan Luo*†a, Xuejun Zhao ${ }^{\mathrm{b}}$

${ }^{\text {a }}$ Osteonecrosis and Joint Reconstruction Ward, Department of Joint Surgery, HongHui Hospital, Xi'an Jiaotong University, Xi'an, Shanxi 710054 China

b Lunan Pharmaceutical Group Co., Ltd. Linyi, Shandong 276006, China.

†Correspondence to: Pan Luo, Email: 1p19940626@163.com

\section{Synthesis and characterization of compounds}<smiles>CC1=Nc2ccccc2C1(C)C</smiles>

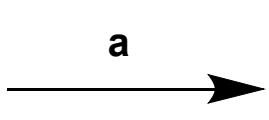<smiles>CC[N+]1=C(C)C(C)(C)c2ccccc21</smiles>

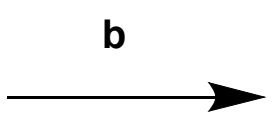

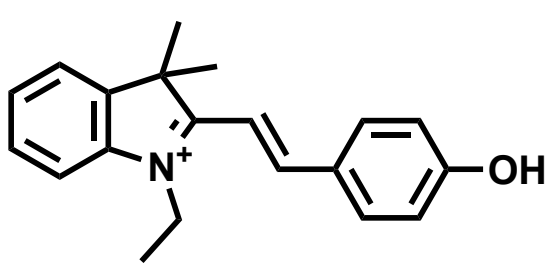

HDI

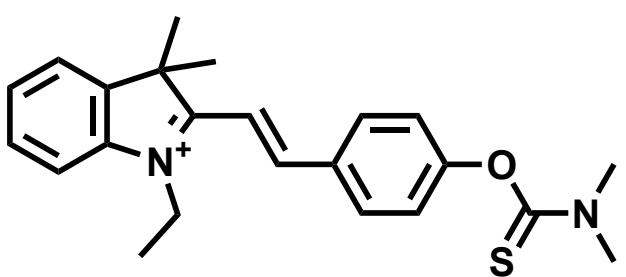

HDI-HCIO

Scheme S1. The general synthetic routes for the probe HDI-HClO. a) toluene, propane sultone, $18 \mathrm{~h}, 90 \%$. b) p-hydroxybenzaldehyde, EtOH, 4 h, 74\%. c) dimethylthiocarbamoyl chloride, $\mathrm{CH}_{2} \mathrm{Cl}_{2}$, piperidine, $37 \%$.

\section{HPLC experiment.}

To further gain insight into the interaction of HDI-HClO toward HClO, HPLC experiments were performed. Herein, Eluent A was 5\% aqueous acetonitrile solution containing $0.1 \%$ formic acid buffer, and eluent $\mathrm{B}$ was pure acetonitrile. Running conditions were as follows: the linear gradient condition: $0 \mathrm{~min}=50 \% \mathrm{~B}, 5 \mathrm{~min}=100 \%$ $\mathrm{B}, 18 \mathrm{~min}=100 \% \mathrm{~B}$; flow rate: $0.5 \mathrm{~mL} \cdot \mathrm{min}^{-1}$ and detection wavelength: $254 \mathrm{~nm}$. As shown in Figure S1, the peak of HDI-HClO and HDI located at $5.43 \mathrm{~min}$ and $6.78 \mathrm{~min}$, respectively. A strong new peak could be observed after the addition of $\mathrm{HClO}$, and the 
retention time of the new peak was consistent with that of HDI. Therefore, in present of $\mathrm{HClO}$, the probe released the exposed hydroxyl group and promoting its fluorescence recovery.

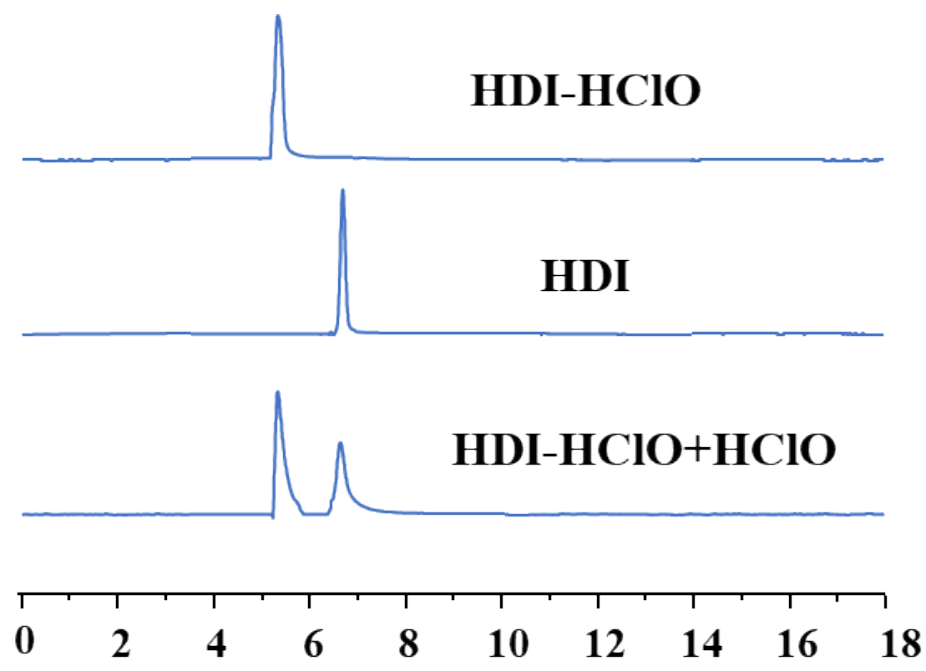

Figure S1. HPLC analysis of the reaction solution from the incubated mixture of HDI$\mathrm{HClO}(10 \mu \mathrm{M})$ with $\mathrm{HClO}(20 \mu \mathrm{M})$ for $1 \mathrm{~min}$, HDI-HClO, and HDI, respectively.

\section{The selectivity of HDI-HCIO to other analytes}
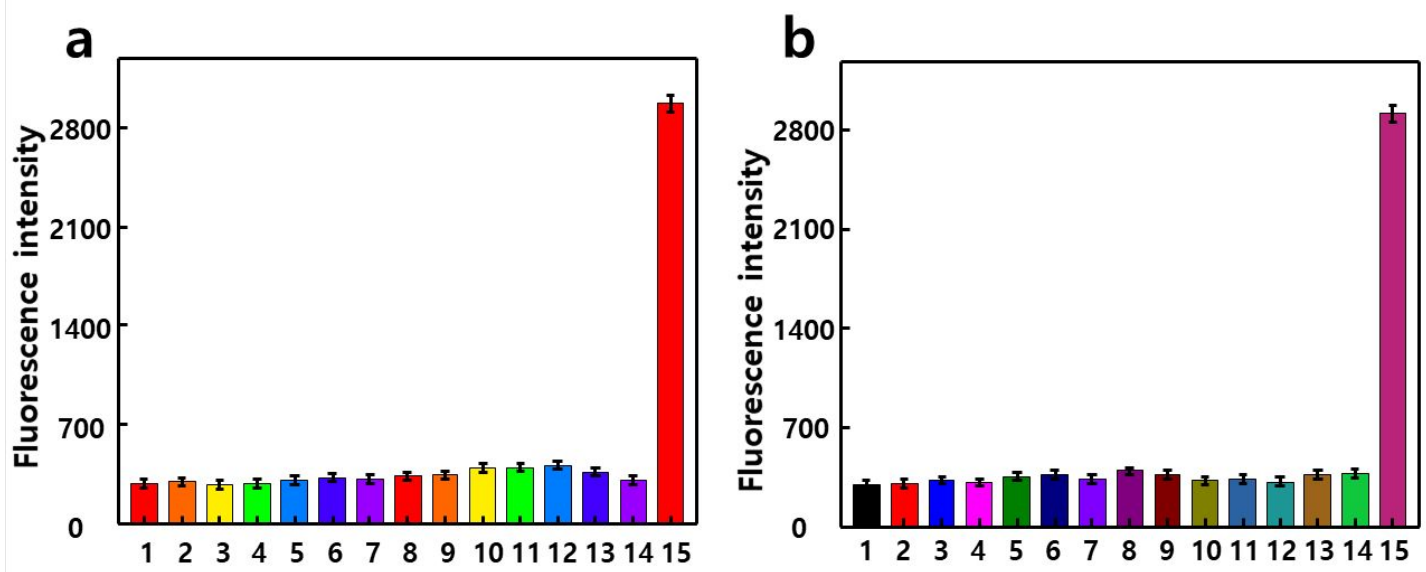

Figure S2. The response of $\mathrm{HDI}-\mathrm{HClO}$ to common ions, anions and amino acid (1 $\mathrm{mM})$ : a) 1, blank; 2, $\mathrm{Na}^{+} ; 3 . \mathrm{K}^{+} ; 4 . \mathrm{Cu}^{2+} ; 5 . \mathrm{Ba}^{2+} ; 6 . \mathrm{Ca}^{2+} ; 7 . \mathrm{Hg}^{2+} ; 8 . \mathrm{Mg}^{2+} ; 9 . \mathrm{Fe}^{3+} ; 10 . \mathrm{S}_{2} \mathrm{O}_{7}^{2-}$; 11. $\mathrm{S}_{2} \mathrm{O}_{8}{ }^{2-} ; 12 . \mathrm{F}^{-} ; 13 . \mathrm{Cl}^{-} 14 . \mathrm{Br}^{-}$and 15. $20 \mu \mathrm{M}$ HClO. b) 1, blank; 2, GSH; 3. Cys; 4. Hcy; 5. Ala; 6. Arg; 7. Trp; 8. Leu; 9. Thr; 10. Ser; 11. Met, 12. Glu; 13. Asp; 14. Lys; and $15.20 \mu \mathrm{M} \mathrm{HClO}$. The experiments were repeated three times and the data were shown as mean ( \pm S.D.).

\section{The response of the probe to Cys, GSH and Hcy.}

Subsequently, we studied the influence of some thiols on the probe for a long time (0$180 \mathrm{~min}$ ). The result suggested that after adding Cys, GSH and $\mathrm{HCy}$ for $60 \mathrm{~min}$, a 
weaker fluorescence signal appeared at $460 \mathrm{~nm}$.

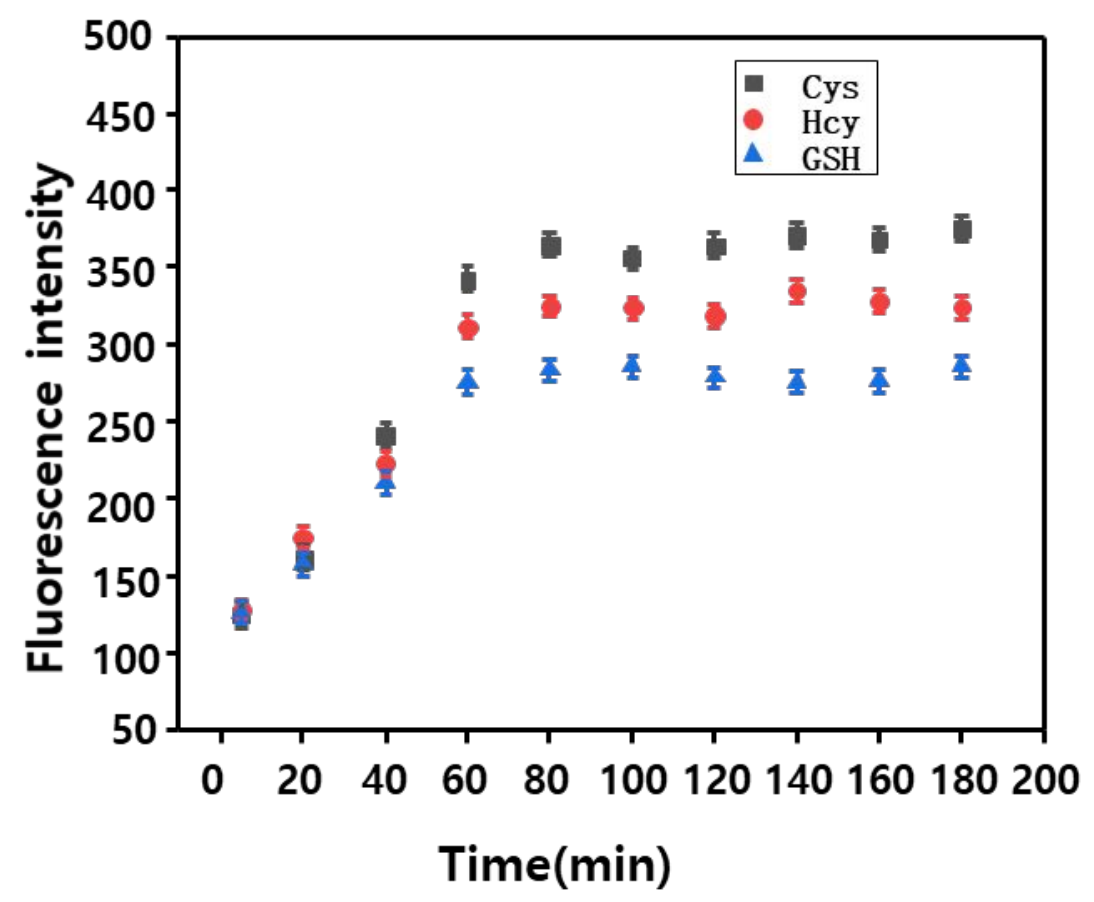

Figure S3. The response of HDI-HClO to Cys, GSH and Hcy within 0-60 min.

4. Cytotoxicity assays

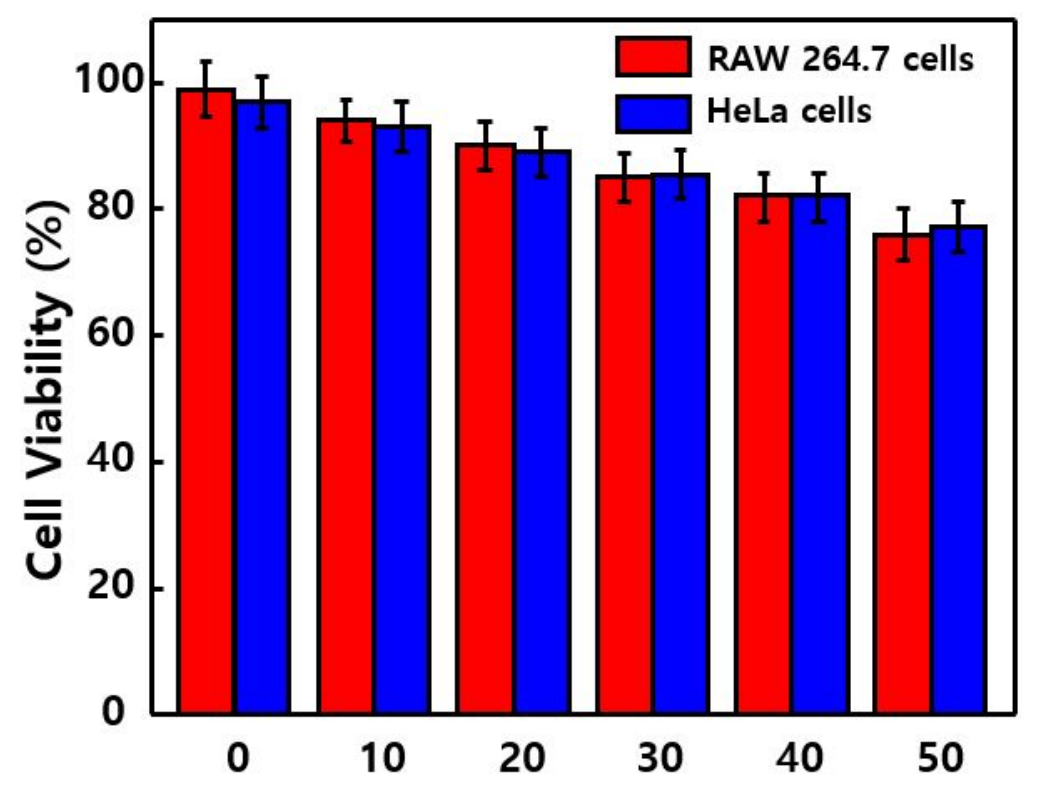

Figure S4. The cell viability of the probe against HeLa cells and RAW 264.7 cells. The experiments were repeated three times and the data were shown as mean ( \pm S.D.).

5. Discussion on different types of fluorescent probes for $\mathrm{HClO}$ detection. 
In here, we compare the proposed $\mathrm{HClO}$ probes with previously reported probes. For example: response time, emission wavelength, response type, detection limit.

Table S1. Comparison of reported fluorescent probes and our proposed probe for HClO.

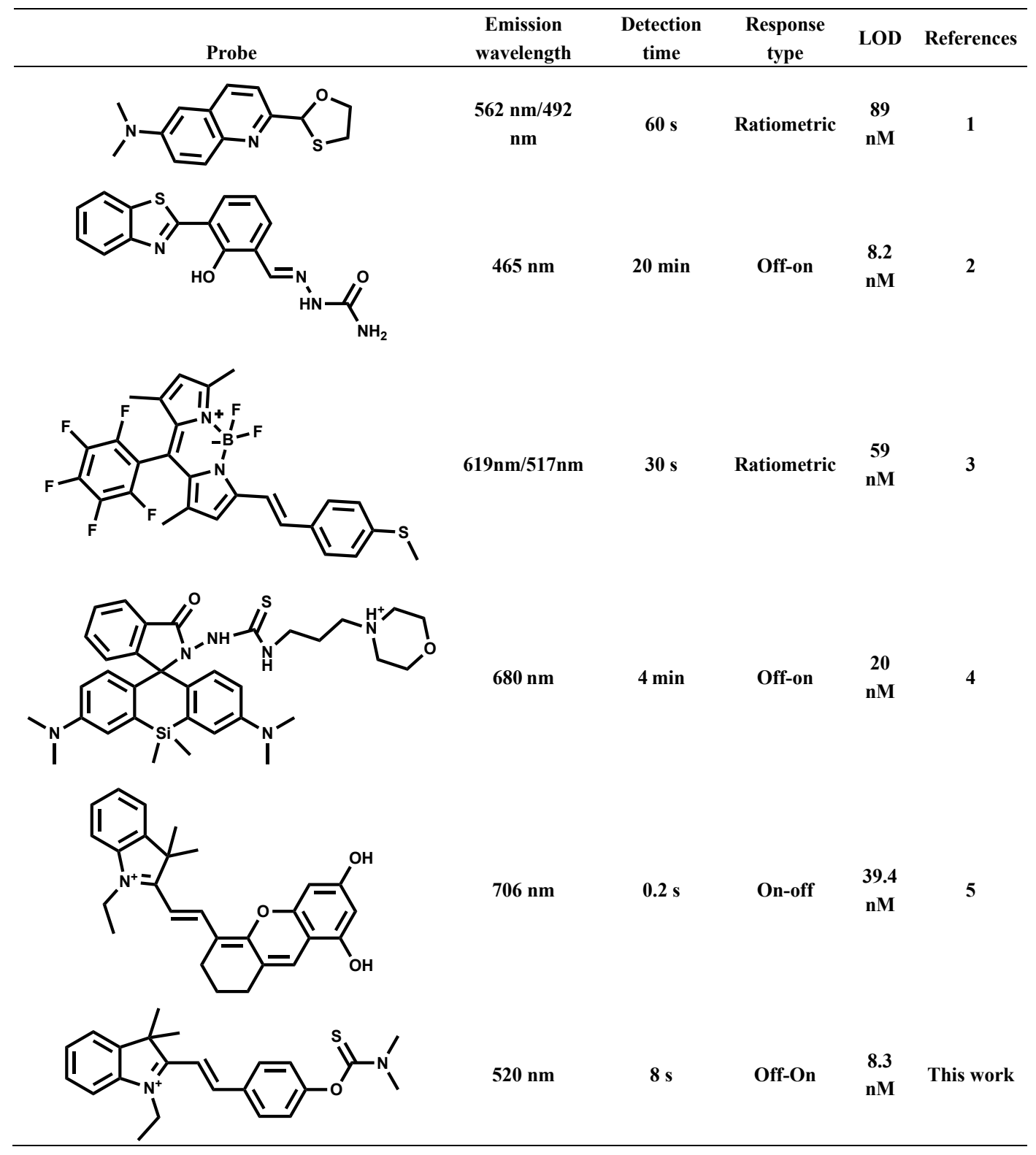

\section{Bright-field cell images of Figure 3 and 4.}



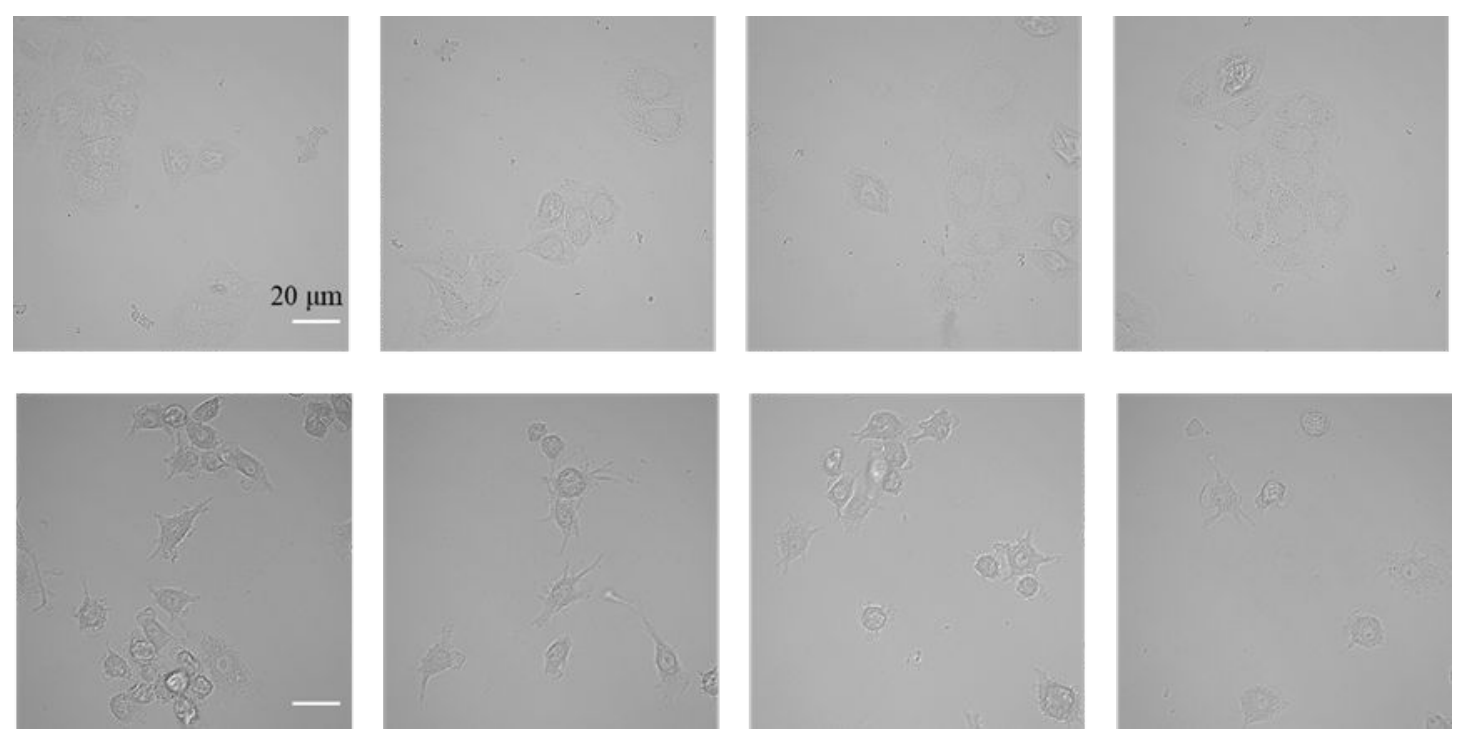

Figure S5. Bright-field cell images of Figure 3 and 4.

\section{7. ${ }^{1} \mathrm{H}$ NMR, ${ }^{13} \mathrm{C}$ NMR and HR-MS}

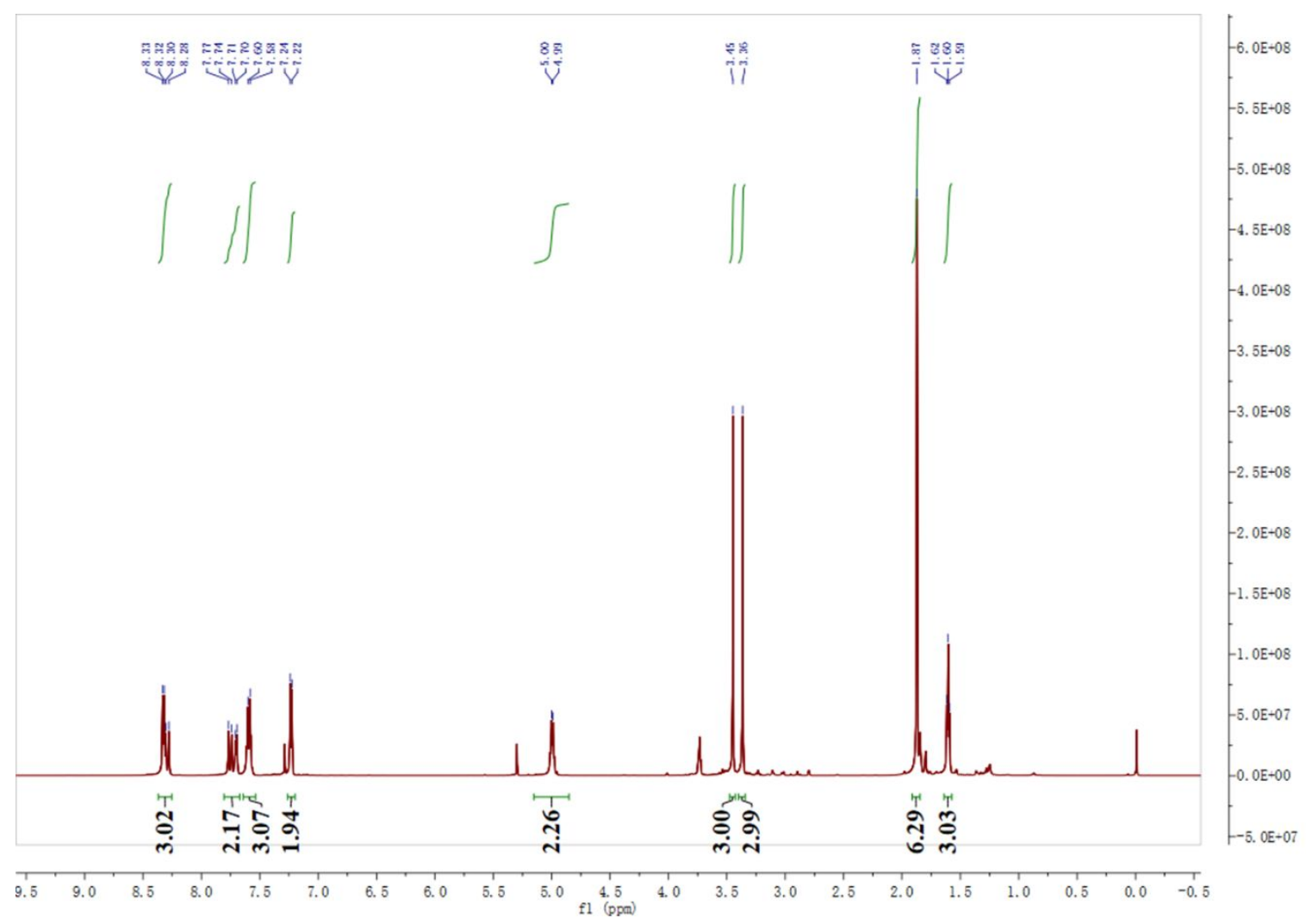

Figure S6. ${ }^{1} \mathrm{H}$ NMR of HDI-HClO.

${ }^{13}$ C NMR of HDI-HCIO 


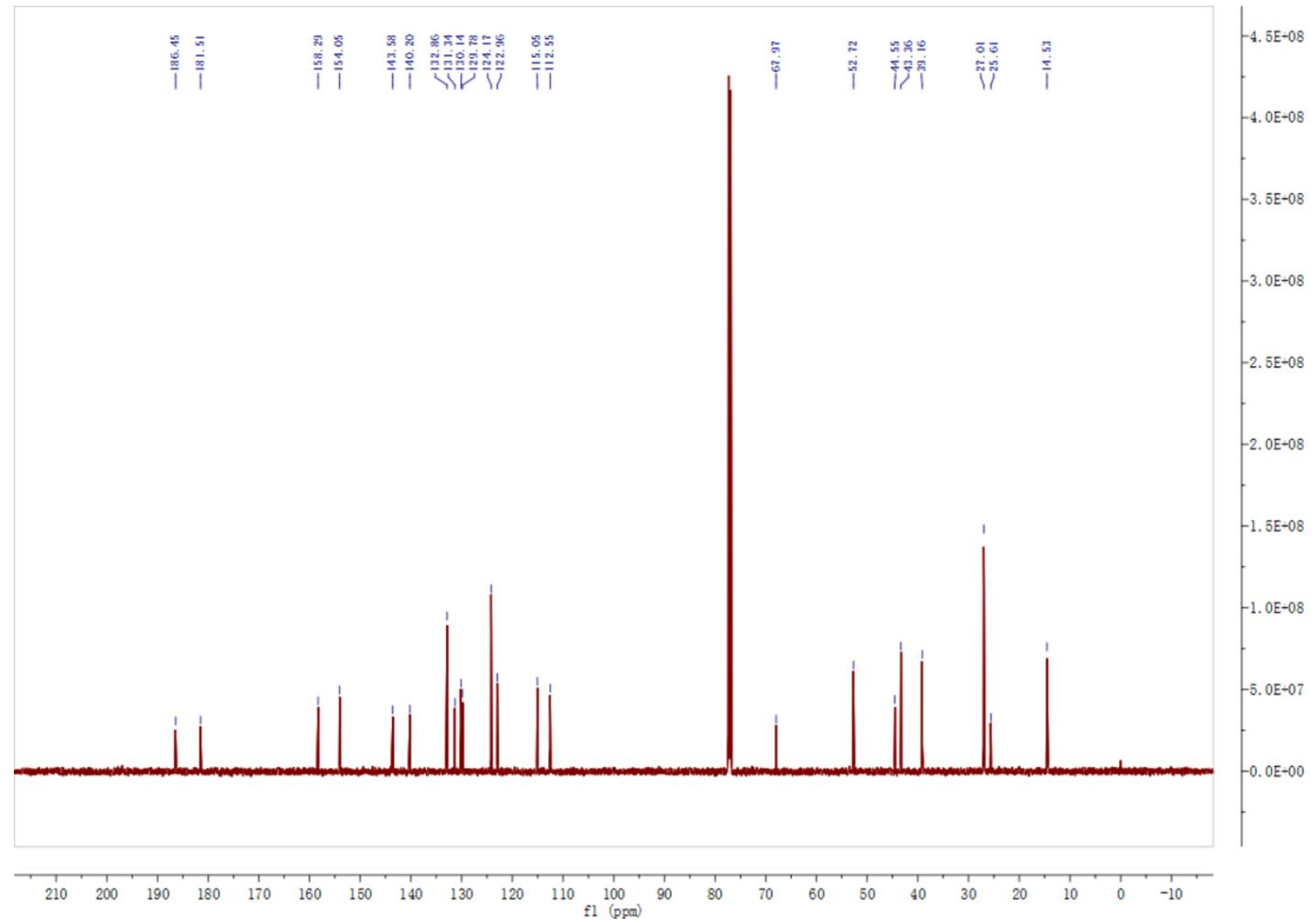

Figure S7. ${ }^{1} \mathrm{H}$ NMR of HDI-HClO.

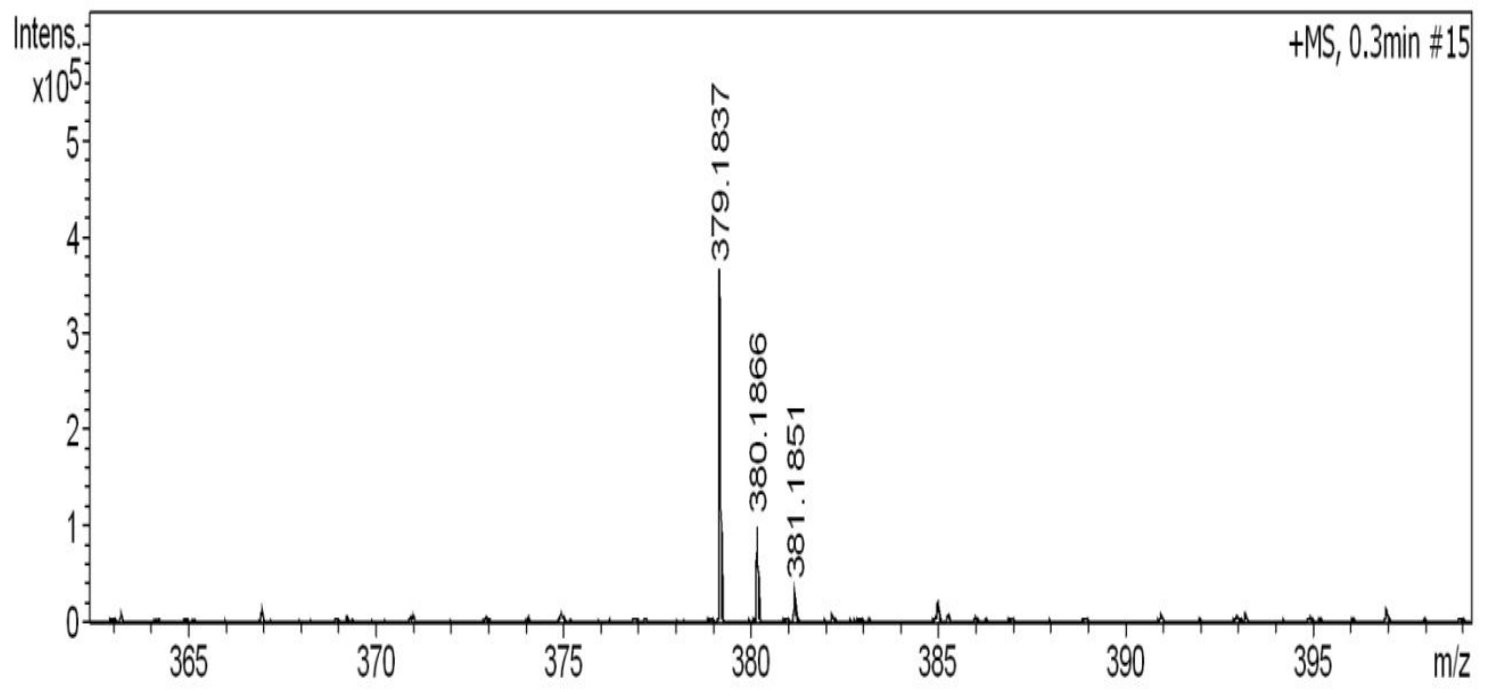

Figure S8. HR-MS of HDI-HClO.

\section{References}


1. Mao, Z.; Ye, M.; Hu, W.; Ye, X.; Wang, Y.; Zhang, H.; Li, C.; Liu, Z. Design of a ratiometric two-photon probe for imaging of hypochlorous acid ( $\mathrm{HClO})$ in wounded tissues. Chem. Sci. 2018, 9 (28), 6035-6040.

2. Yang, Y.; Qiu, F.; Wang, Y.; Feng, Y.; Song, X.; Tang, X.; Zhang, G.; Liu, W. A sensitive and selective off-on fluorescent probe for $\mathrm{HClO}$ in $100 \%$ aqueous solution and its applications in bioimaging. Sens Actuators B Chem. 2018, 260 (23), 832-840.

3. Duan, C.; Won, M.; Verwilst, P.; Xu, J.; Kim, H. S.; Zeng, L.; Kim, J. S., In Vivo Imaging of Endogenously Produced $\mathrm{HClO}$ in Zebrafish and Mice Using a Bright, Photostable Ratiometric Fluorescent Probe. Anal. Chem. 2019, 91 (6), 4172-4178.

4. Mao, G. J.; Liang, Z. Z.; Bi, J.; Zhang, H.; Meng, H. M.; Su, L.; Gong, Y. J.; Feng, S.; Zhang, G. A near-infrared fluorescent probe based on photostable Si-rhodamine for imaging hypochlorous acid during lysosome-involved inflammatory response. Anal. Chim. Acta. 2019, 1048, 143-153.

5. Ma, J.; Yan, C.; Li, Y.; Duo, H.; Li, Q.; Lu, X.; Guo, Y. Unusual Hypochlorous Acid (HClO) Recognition Mechanism Based on Chlorine-Oxygen Bond (Cl-O) Formation. Chemistry. 2019, 25 (29), 7168-7176. 